\section{Attitudes of Medical Students Towards Gastroenterology Teaching in the UK: A BSG Survey}

V. T. F. Cheung ${ }^{* 1}$, G. J. Johnson²

${ }^{1}$ Gastroenterology, John Radcliffe Hospital, Oxford ${ }^{2}$ Gastroenterology, University College Hospital, London, United Kingdom
Oxford University Hospitals N/iss

NHS Trust

University College London Hospitals Wils

NHSFoundition Trust

\section{INTRODUCTION}

- Little is known about undergraduate gastroenterology teaching in the UK

This project aims to inform how the BSG could assist with undergraduate teaching across the UK, and ultimately inspire tomorrow's doctors to choose a career in gastroenterology

Q6 Do you think that there is there quate exposure to Gastroenterology in your medical school training? Answered: 101 Skipped: 9

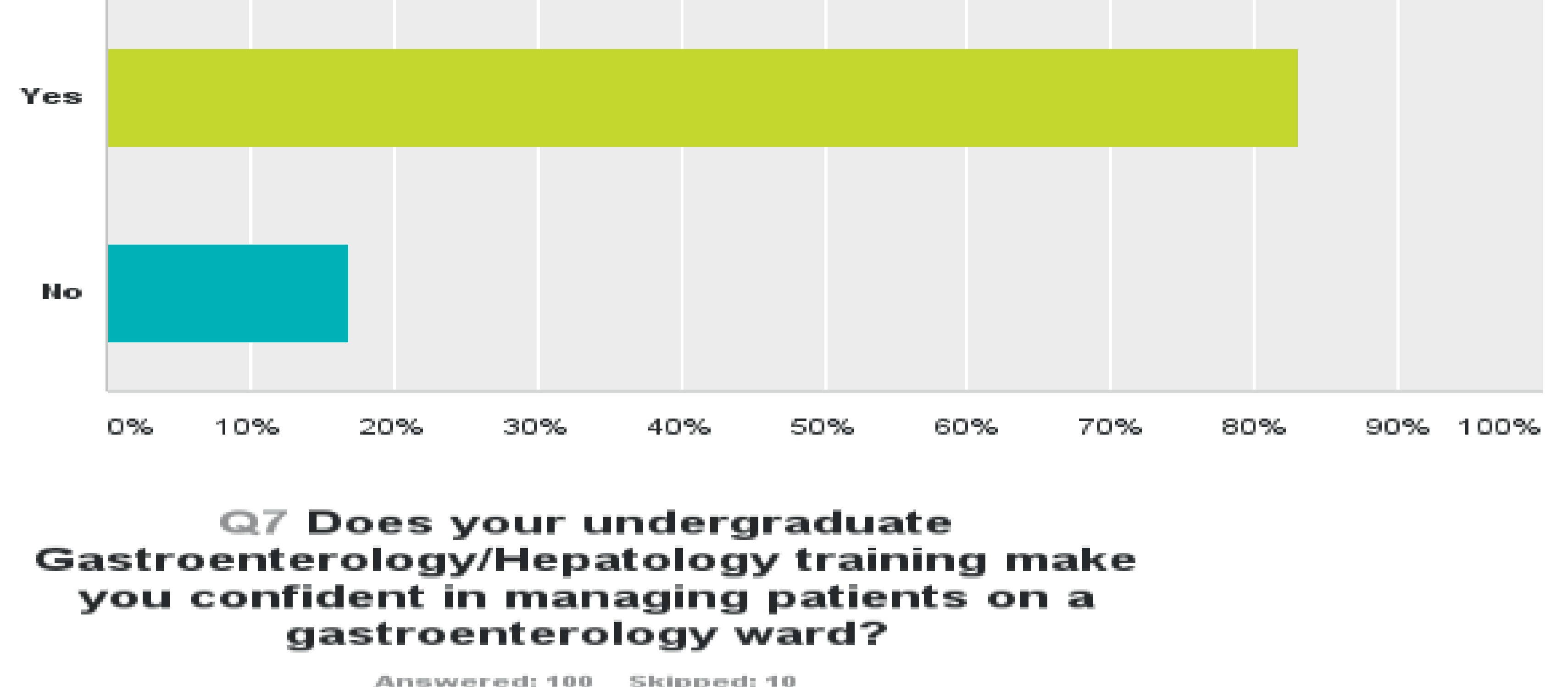
gastroenterology ward?

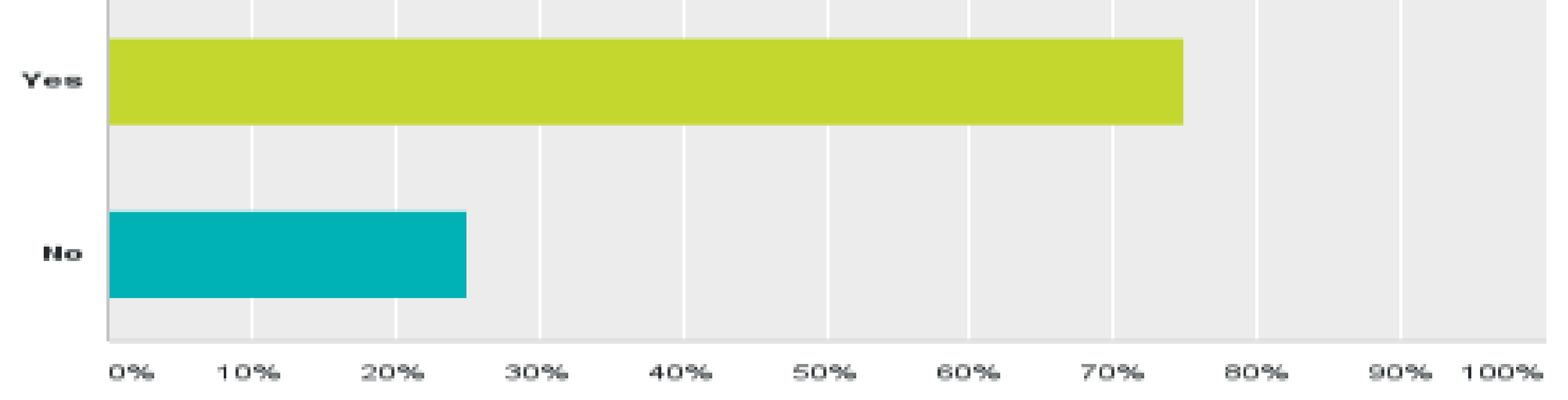

\section{METHODS}

An electronic survey (containing 27 questions on undergraduate gastroenterology training) was sent to medical students by UK medical school deans and local gastroenterology champions

- Responses over 10 weeks $=110$ students from 12/35 medical schools responded $(1 \% \mathrm{Y} 1,3 \% \mathrm{Y} 2,30 \% \mathrm{Y3}, 25 \% \mathrm{Y} 4,36 \% \mathrm{Y} 5$, Y 6 $5 \%)$

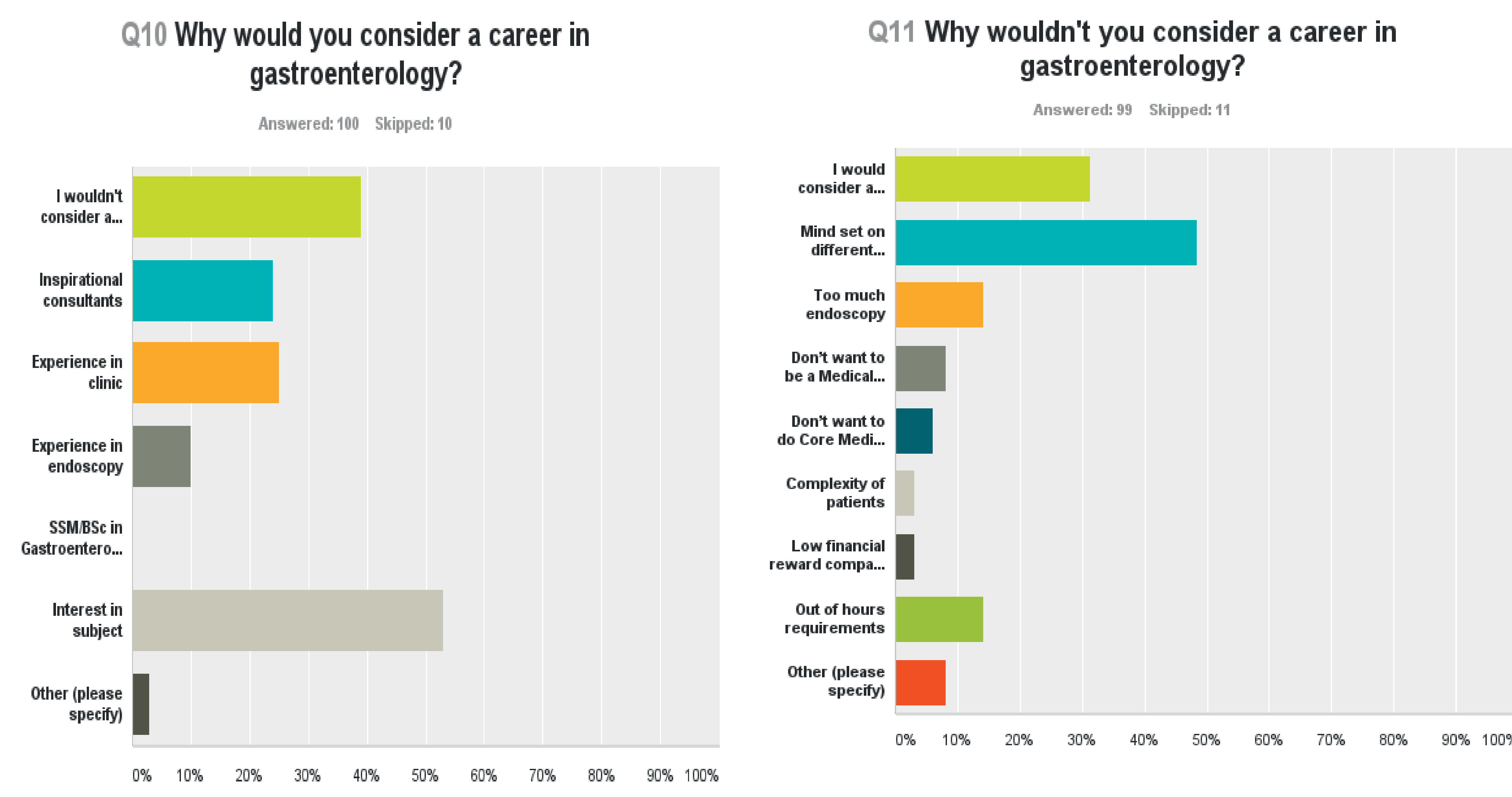

\section{RESULTS}

- $9 \%$ had a student gastroenterology society, $42 \%$ did not and $49 \%$ were unsure

- Of the ones with a student society, $18 \%$ interacted via email, $4 \%$ had a website and $21 \%$ had a Facebook group

- $83 \%$ felt there was adequate exposure to gastroenterology in their training

- $75 \%$ felt confident in managing gastroenterology patients on the wards from training

- $59 \%$ would consider a career in gastroenterology with interest in the subject being the overriding reason (53\%)

- $41 \%$ would not consider a career in gastroenterology with mind set on different specialty the most common reason (49\%)

- $71 \%$ had an integrated curriculum and $29 \%$ a traditional preclinical then clinical one

- Training includes lectures (98\%), group work (65\%), PBL (63\%), bedside (62\%) and dissection (33\%)

- Not all students get a gastroenterology block but those who do spend mean 4.6 weeks

- $65 \%$ had integrated gastroenterology and surgical teaching

- $72 \%$ had a copy of the gastroenterology syllabus within their MBBS curriculum and $60 \%$ had read them

- In finals, 83\% had SBAs, 77\% OSCEs, 65\% MCQs, 36\% short answers and 3\% essays
4 Dos your medical school have a student gastroenterology society?

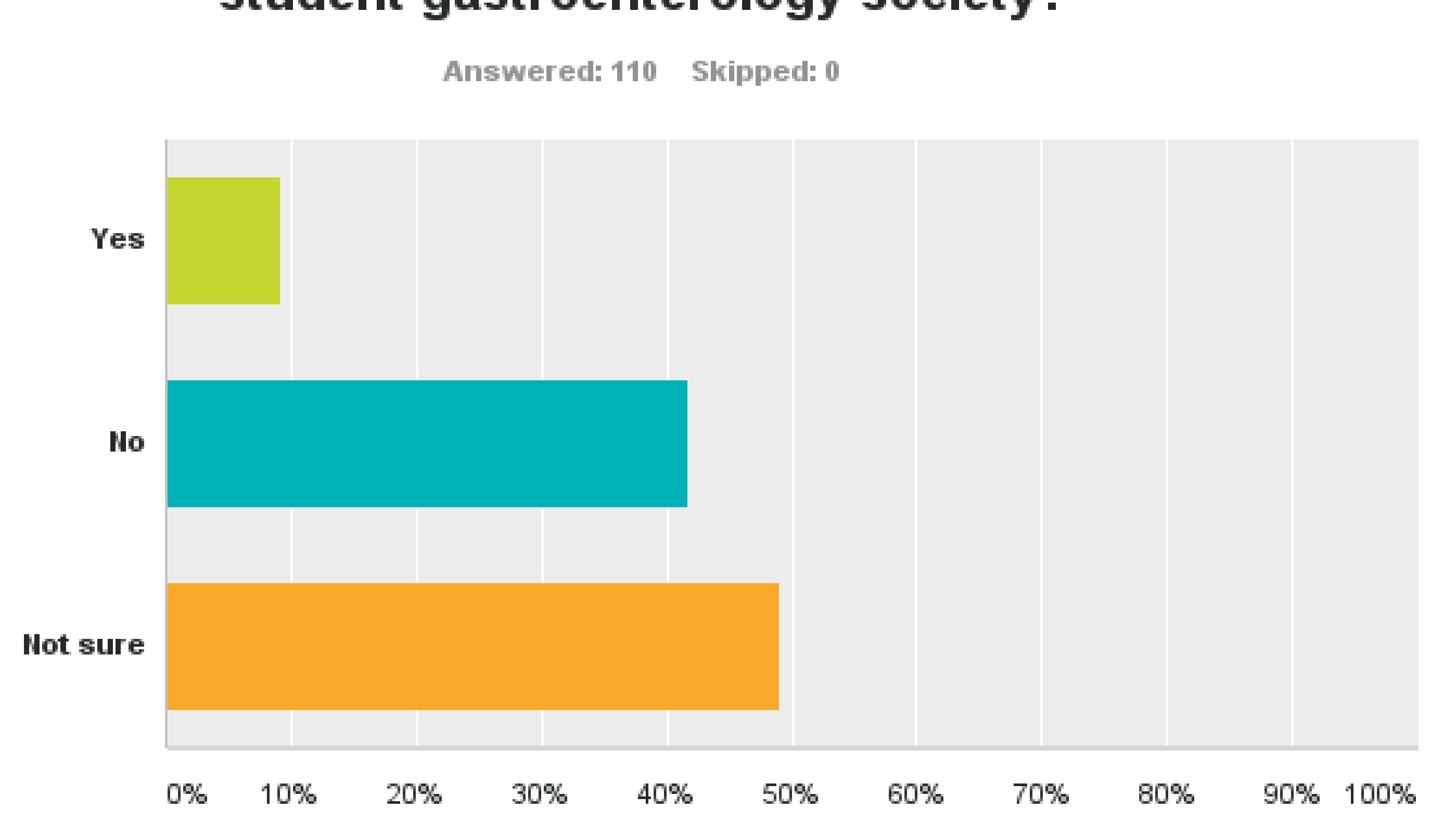

\section{CONCLUSIONS}

- $\quad$ Training appears to give adequate exposure to gastroenterology and enable medical students to feel confident in managing such patients

- $\quad$ Suggestions from students regarding improvements in training were:

Mandatory gastroenterology attachment More hepatology

More bedside teaching

BSG to do taster days/revision courses/simulation days

Student gastroenterology conferences with career talks

9\% had a student gastroenterology society so BSG can help in promoting these

- Almost 2/3 would consider a career in gastroenterology so BSG should target these students and establish links early in their training 